\title{
MODELING AND DIRECT TORQUE CONTROL OF INDUCTION MOTOR BY USING HYBRID CONTROL TECHNIQUE
}

\author{
D. Chandra Sekhar ${ }^{1}$ and G.V. Marutheshwar ${ }^{2}$ \\ ${ }^{1}$ Research Scholar, Department of EEE, S.V. University,Tirupati, India \\ ${ }^{2}$ Professor, Department of EEE, S.V. University, Tirupati,, India
}

\begin{abstract}
In this paper, an adaptive neuro fuzzy interference (ANFIS) based hybrid field oriented speed controlling of an induction motor is proposed. The proposed hybrid field oriented speed controller results attractive performance of induction motor with the potential features of both Artificial Neural network (ANN) and Fuzzy Logic Controller (FLC). In this topology the Artificial Neural Network (ANN) used to estimate the suitable inputs to control the system and Fuzzy Logic Controller used to evaluating the system inputs in terms of logic variables. In the proposed Direct Torque Controller (DTC) scheme the actual motor torque and change in torque is possess through the proposed adaptive neuro fuzzy interference system. Then the speed of the induction motor is controlled by using the controlled electromagnetic torque i.e.,output of the ANFIS controller. The entire proposed system is implemented in MATLAB/SIMULINK environment. And simulation results are also presented to demonstrate the attractive performance of the proposed ANFIS based DTC speed control of the induction motor. And also the comparative steady and dynamic performance of conventional Fuzzy Logic Controller and ANFIS based controller is presented.
\end{abstract}

\section{KEYWORDS}

ANFIS, DTC, Fuzzy logic controller \& Induction motor.

\section{INTRODUCTION}

Induction Motorplays a major role in industrial applications when compared to other AC motors due to its simple and robust construction. However, the control of IM is complex due to the nonlinear nature and the parameters changes with operating conditions [4]. An Induction Motor (IM) is an AC motor, where power is supplied to the rotor by means of electromagnetic induction [2]. The motor efficiency can be improved by reducing the flux and by balancing the motor iron and copper losses [19]. The impreciseness of the estimation of the electrical parameters of the machine will degrade the speed control performance [7]. In general the mechanical speed of the motor is varied under this the estimation of speed is more complex due to the speed of revolving magnetic field is not equal to the rotor speed [18].

In recent years many have been carried out to develop different solutions for the induction motor control for quick torque response by reducing circuit complexity of field oriented algorithms. Direct Torque Control (DTC) technique controls the torque and speed of the motor, which is directly based on the electromagnetic state of the motor [1]. The name direct torque control is derived from the fact that on the basis of the errors between the 
reference and the estimated values of torque and flux, it is possible to directly control the inverter states in order to reduce the torque and flux errors within the permissible limits [8]. The DTC method is a simple and give fast transient response against the speed variations of the motor, hence most of the industrial drives are equipped with DTC [15]. However, the main limit of conventional DTC scheme is high torque ripple, variable switching frequency and the torque does not match the torque demand [5][15].

So, in this paper main focus on reducing the swing levels of the flux and torque, for that improving the dynamic performance. For the controller the PWM pulse generation places a major role to control the speed with reduced flux and torque fluctuation. The different induction motor control techniques such as DTC with space vector pulse width modulation (SVPWM) technique, artificial intelligence techniques etc., [5] [9] were in development currently. In this paper proposes the ANFIS based Hybrid field oriented speed controller. The proposed ANFIS based DTC are robust and fast torque response, no requirements for coordinate transformation, requirements for PWM pulse generation and current regulators. The present paper concerns with the implementation of Fuzzy and ANFIS techniques to improve the speed/torque characteristics of the induction motor.

\section{Mathematical Model of DTC OF InduCtion Motor}

The mathematical model of the induction machine is used for analyzing the dynamic behavior of the motor. The dynamic behavior of the motor affects the changes in motor parameters such as speed, torque, resistance, flux etc. So, the dynamic model is essential for analyzing the performance of the induction motor. The dynamic model of the induction motor is derived by transforming the three phase quantities into two phase direct and quadrature axes quantities by using Clark's transformation. The mathematical equation of DTC of the induction motor is given below.

\subsection{Voltage equations:}

The mathematical equations of the stator and rotor voltages as follows:

$$
\begin{aligned}
& V_{s \alpha}=r_{s} i_{s \alpha}+P \psi_{s \alpha} \\
& \text { (1) } \\
& V_{s \beta}=r_{s} i_{s \beta}+P \psi_{s \beta} \\
& V_{r \alpha}=r_{r} i_{r \alpha}+P \psi_{r \alpha}+\psi_{r \beta} \omega_{r} \\
& V_{r \beta}=r_{r} i_{r \beta}+P \psi_{r \beta}-\psi_{r \alpha} \omega_{r}
\end{aligned}
$$

Where, $V_{s \alpha}, V_{s \beta}, V_{r \alpha}$ and $V_{r \beta}$ are the $\alpha$-axis and $\beta$ - axis voltages of stator and rotor respectively. Then, $i_{s \alpha}, i_{s \beta}, i_{r \alpha}$ and $i_{r \beta}$ are the $\alpha$-axis and $\beta$-axis currents of stator and rotor respectively. The resistance and inductance of the stator and rotor winding are denoted by $r_{s}, r_{r}$, and $L_{r}$ respectively. The stator and the rotor flux of the motor are described as $\psi_{s \alpha}, \psi_{r \alpha}, \psi_{s \beta}$ and $\psi_{r \beta}$ respectively.

The stator flux equations are rewritten as follows: 


\subsection{Stator Flux:}

$\psi_{s \alpha}=\int\left(V_{s \alpha}-r_{s} i_{s \alpha}\right) d t$
$\psi_{s \beta}=\int\left(V_{s \beta}-r_{s} i_{s \beta}\right) d t$

(6)

The magnitude of the stator flux $\left(\psi_{s}\right)$ is the combination of $\alpha$-axis and $\beta$-axis flux which is expressed as follow,

$$
\left|\psi_{s}\right|=\sqrt{\psi_{s \alpha}^{2}+\psi_{s \beta}^{2}}
$$

(7)

The magnetic track phase angle $(\theta)$ is expressed as follow,

$$
\theta=\arctan \left(\psi_{s \alpha} / \psi_{s \beta}\right)
$$

The electromagnetic torque of the motor is estimated from the inductance and the $\alpha-$ $\beta$ axis current. The $\alpha-\beta$ axis currents of the motor is obtained from the flux linkages that transpired in the stator and rotor of the motor. The expression of the electromagnetic torque that is produced by the motor is given as follows.

\subsection{Electromagnetic Torque:}

$$
T_{e}=3 / 2 \cdot P / 2\left(\psi_{s \alpha} i_{s \beta}-\psi_{s \beta} i_{s \alpha}\right)
$$

The actual torque developed by the motor in terms of rotor speed is illustrated as follow.

$$
T=T_{e}-T_{L}=P / 2\left(J \frac{d \omega_{r}}{d t}+B \omega_{r}\right)
$$

Where, $P$ is the number of poles, $J$ is the moment of inertia of rotor, $B$ is the damping coefficient, $\omega_{r}$ is the rotor speed, $T_{L}$ is the load torque, $T_{e}$ is the electromagnetic torque.

\subsection{Vector Diagram:}

The vector diagram of flux linkages in the stator and rotor winding is illustrated in fig.1. The three phase currents $i_{a}, i_{b}$ and $i_{c}$ are converted to a two-phase orthogonal system with axes $\alpha$ and $\beta$ by the Clark's Transformation technique. Here $\alpha$ component is assumed as it is equal to the axis a as per our convenience as shown in fig. 1. Obtained orthogonal 
currents $i_{\alpha}$ and $i_{\beta}$ are again transformed into a time-invariant, rotating orthogonal system corresponds to the field and torque components $d$ and $q$ of the equivalent rotor currents $i_{d}$ and $\mathrm{i}_{\mathrm{q}}$. The $\alpha / \beta$ coordinate frame is rotated counterclockwise to line up with the rotor flux axis $\psi_{r}$. The angle of rotation $(\theta)$ is determined with the help of the motor model.

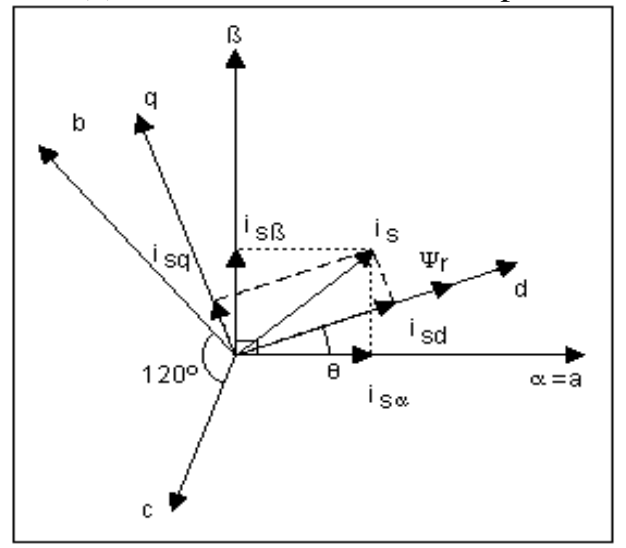

Figure 1: Vector Diagram of DTC of Induction Motor

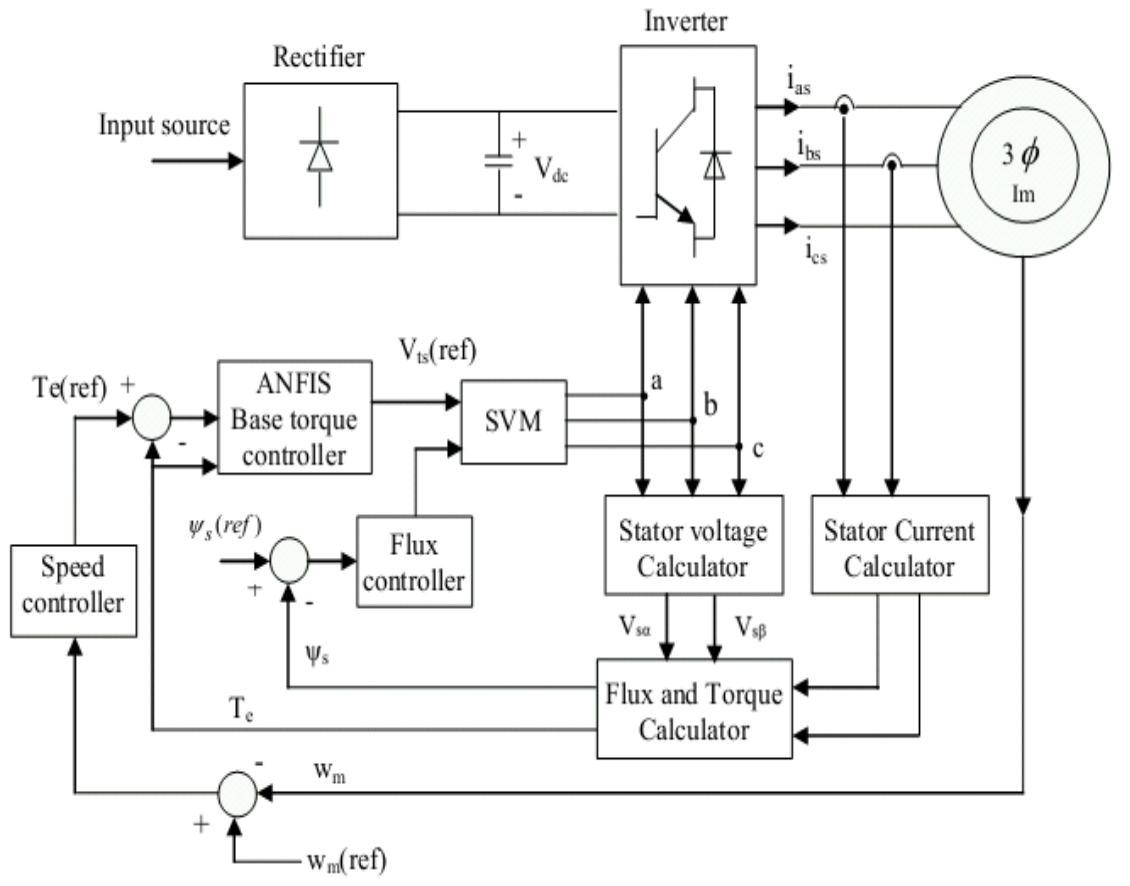

Figure 2: Proposed ANFIS Based DTC System

The overall control designing of the proposed ANFIS controller is shown in fig.2. In the proposed model stator voltage and current calculators estimates the two-phase orthogonal system components with axes $\alpha$ and $\beta$ respectively. With this components the actual torque and the flux is evaluated. The reference values of the torque are depends upon the load variation. So, here the optimization of reference torque is required. For the optimization of the reference torque the speed controller is adopted. The speed controller estimates the reference values of torque. By comparing reference torque values with the actual values estimating the change torque. The estimated actual torque and change torque 
is applied to the proposed ANFIS controller, this produces the controlled torque. This controlled torque is fed to PWM controller to generate control signals for gate terminals of the inverter. Here, the space vector PWM modulation technique is used for generating the gate control signal. The SVM based switching table is referred from [29] switching output, the IGBT gate is controlled.

\section{ADAPTIVE NEURO FUZZY INTERFERENCE SYSTEM}

This section describes the detail description of the proposed ANFIS model. Adaptive neurofuzzy interference system is the combination of neural network (NN) and fuzzy logic controller (FLC) [28]. The adaptive neuro-fuzzy interference system facilitates the attractive control performance with the potential features of both Artificial Neural network (ANN) and Fuzzy Logic Controller (FLC). The enactment of the ANN and Fuzzy logic in the interference system based on the feed forwarding technique. The fuzzy structure and neurons of neural network are implemented based on feed forward technique. In the hybrid system, the data set is developed by neural network in terms of actual torque and change of torque and reference torque of the motor. The generated data set is fed to fuzzy interference system and the fuzzy control rules are generated. This adaptive system is generated in two phases, one is training phase and other is testing phase. The training and testing phase are explained as follows.

\section{1. Training Phase:}

The first phase of ANFIS is training phase which used for generating training data set. In the proposed control approach, the actual torque and change of torque of the motor values are generated in the form of vector and the data is applied to the neural network. Then, the data is trained by back propagation training algorithm with respect to the actual torque of motor. Then, the trained data is applied to the fuzzy interference system for generating the control fuzzy rules. In ANFIS, the fuzzy rules base control interference system is automatically generated.

\subsection{Testing Phase:}

The next phase of ANFIS is testing which used for creating the test speed control system model. In the testing phase, the actual torque and the change of torque of the motor is applied as the input, the appropriate control electromagnetic torque is obtained from the interference system.

\section{3. Features of ANFIS}

In the proposed speed control system, the ANFIS is used for the set of features which is based on neural network and fuzzy system. The feature of the neural network is the structure network of feed forward type and the network training algorithm is back propagation. In the back propagation training algorithm, the data is trained based on the network error. The error of the network is the difference between the target value and the actual value. Hence, the appropriate control model can be to developed. The model proposed in fuzzy interference system is based on the Sugeno model [30] which contains a set of rules. The fuzzy concept consists of three steps i.e. fuzzification, rule base decision making and fuzzification. In the fuzzy process, the vector of the firing strengths is normalized and the resulting vector is defuzzyfied by utilizing the first order Sugeno model. The normalization processes consist of fuzzification and decision stage. 


\section{4. Structure of ANFIS:}

The structure of ANFIS system consist of five layers which are categorized as input layer, input membership function layer, rule layer, output members function layer and output layer respectively. The fuzzy interference decision tree is to classify the data into one of $2^{n}\left(\right.$ or $\left.P^{n}\right)$ linear regression models to minimize the sum of squared errors (SSE).

$S S E=\sum_{i} e r_{i}^{2}$

(11)

Where, $n$ is the number of input variables, $P^{n}$ is the number of fuzzy divisions for each input variable and $e r_{i}^{2}$ is the error between the desired and actual output respectively. The first order two input sugeno fuzzy model is given as in follow.

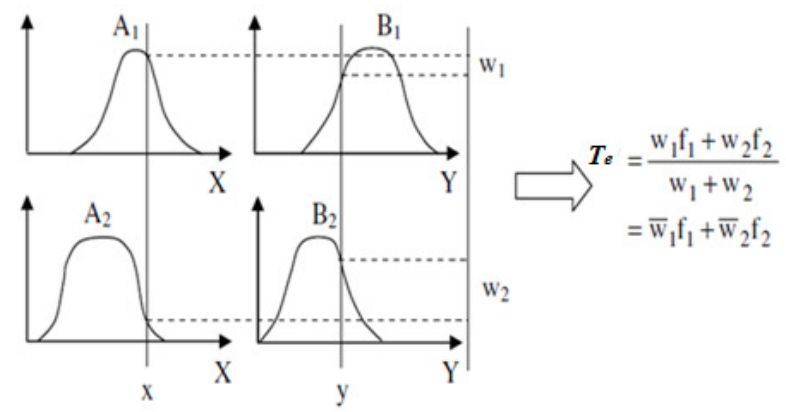

Figure 3: Two input first order Sugeno fuzzy model with two rules.

The typical fuzzy if-then rule set for the first order Sugeno fuzzy inference model [31], can be stated below,

If $x_{1}$ is $A_{1} A N D x_{2}$ is $B_{1}$, then $f_{1}=p_{1} T_{e}^{*}+q_{1} \Delta T_{e}^{*}+r_{1}$

If $x_{1}$ is $A_{2} A N D x_{2}$ is $B_{2}$, then $f_{2}=p_{2} T_{e}^{*}+q_{2} \Delta T_{e}^{*}+r_{2}$

Where, $A_{i}$ and $B_{i}$ are the antecedent fuzzy sets and parameters $p_{i}, q_{i}$ and $r_{i}$ are the fuzzy design parameters calculated during the training process $(\mathrm{i}=1,2, \ldots \mathrm{n})$. The two input and single output ANFIS structure is given as following them.

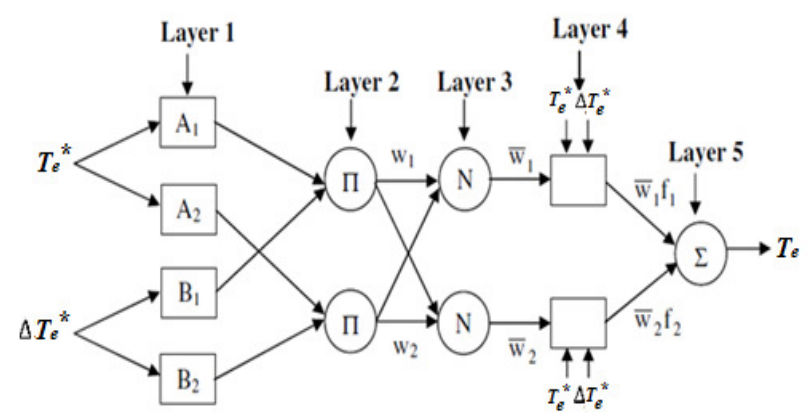

Figure 4: Structure of ANFIS. 
In Figure 4, the mechanism for obtaining the actual torque $\left(T_{e}\right)$ of the motor for a given input vector $\left[T_{e}^{*}, \Delta T_{e}^{*}\right]$ Sugeno model is illustrated. The structure of the ANFIS and the each layers are explained as following.

Layer 1:In this layer, the adaptive nodes with node functions are consisted; the node function is defined as following:

$O_{i}^{\text {layer } 1}=\mu_{A_{i}}\left(T_{e}^{*}\right)$

$O_{i}^{\text {layer } 1}=\mu_{B_{i}}\left(\Delta T_{e}^{*}\right)$

(13)

Where, $\omega^{*}$ is the input to node $i \& A_{i}$ is the linguistic label related to that node function. The membership function $O_{i}^{\text {layer } 1}$ indicates the extent to which the specified $T_{e}^{*}$ satisfies the quantifier $A_{i}$. Generally, a bell-shaped $\mu_{A_{i}}\left(T_{e}^{*}\right)$ that has a maximum of 1 and a minimum of 0 is considered as shown below.

$\mu_{A_{i}}\left(T_{e}^{*}\right)=\frac{1}{1+\left|\frac{T_{e}^{*}-c_{i}}{a_{i}}\right|^{2 b_{i}}}=\exp \left\{-\left(\frac{T_{e}^{*}-c_{i}}{a_{i}}\right)^{2 b_{i}}\right\}$

Where, the parameter set $\left\{a_{i}, b_{i}, c_{i}\right\}$ which modifies the membership functions on linguistic label $A_{i}$ is known as premise parameter. Similarly, the value of $\mu_{B_{i}}\left(\Delta T_{e}^{*}\right)$ is selected.

Layer 2: By multiplying the input signals and sending out the product by each node of the layer, the firing strength of the rule is calculated.

$O_{i}^{\text {layer } 2}=w_{i}=\mu_{A_{i}}\left(T_{e}^{*}\right) \mu_{B_{i}}\left(\Delta T_{e}^{*}\right), i=1,2$

Layer 3: The $i^{\text {th }}$ node of this layer is used to determine the ratio between the firing strength of the $i^{\text {th }}$ rule and the sum of firing strengths of all rules.

$O_{i}^{\text {layer } 3}=\overline{w_{l}}=\frac{w_{i}}{w_{1}+w_{2}} i=1,2$

The output of this layer is expressed in terms of normalized firing strengths.

Layer 4: The involvement of $i^{\text {th }}$ rule in the overall output is calculated by the $i^{\text {th }}$ node of this layer as follows,

$O_{i}^{\text {layer } 4}=\bar{w}_{l} f_{i}=\bar{w}_{i}\left(p_{i} T_{e}^{*}\right)+q_{i} \Delta T_{e}^{*}+r_{i}$

Where, $\bar{w}_{l}$ is the output of layer 3 and $\left\{p_{i}, q_{i}, r_{i}\right\}$ are the parameter set of the layer 3 . The term consequent parameters are used to indicate the parameters of this layer.

Layer 5: By taking the summation of all the inputs by the single node that exists in this layer indicated as $\Sigma$, the overall output is calculated. 
Overall output $=O_{i}^{\text {layer } 5}=\sum_{i} \bar{w}_{i} f_{i}=\frac{\sum_{i} w_{i} f_{i}}{\sum_{i} w_{i}}$

For the ANFIS structure shown in Figure 4, the fact that the overall output $f$ can be expressed as a linear combination of the consequent parameters for the case of fixed premise parameters is a most evident from. The output of ANFIS can be represented more precisely as,

$T_{e}=\bar{w}_{1} f_{1}+\bar{w}_{2} f_{2}$

i.e $T_{e}=\left(\bar{w}_{1} T_{e}^{*}\right) p_{1}+\left(\bar{w}_{1} \Delta T_{e}^{*}\right) q_{1}+\left(\bar{w}_{1}\right) r_{1}+\left(\bar{w}_{2} T_{e}^{*}\right) p_{2}+\left(\bar{w}_{2} \Delta T_{e}^{*}\right) q_{2}+\left(\bar{w}_{2}\right) r_{2}$

In the proposed control system, the ANFIS structure is trained by giving the vector as input. Then, the appropriate control output is applied to SVPWM for generating control signal. The generated control signal is applied to the inverter to control the speed of induction motor.

\section{Simulation}

Fig. 5 shows the simulation diagram of Fuzzy logic controller based DTC technique of induction motor. The speed control performance of the fuzzy logic controller is tested with induction motor $2.2 \mathrm{Kw} / 400 \mathrm{~V}$.the performance of the controller is observed under different reference speeds. The proposed ANFIS based hybrid DTC technique was implemented and tested in MATLAB/SIMULINK environment and it is illustrated in Fig.6. The speed control performance of proposed control technique was compared with fuzzy controllerto demonstrate the attractive performance of the proposed system. The implementation parameters of proposed model is depicted in appendix-A.

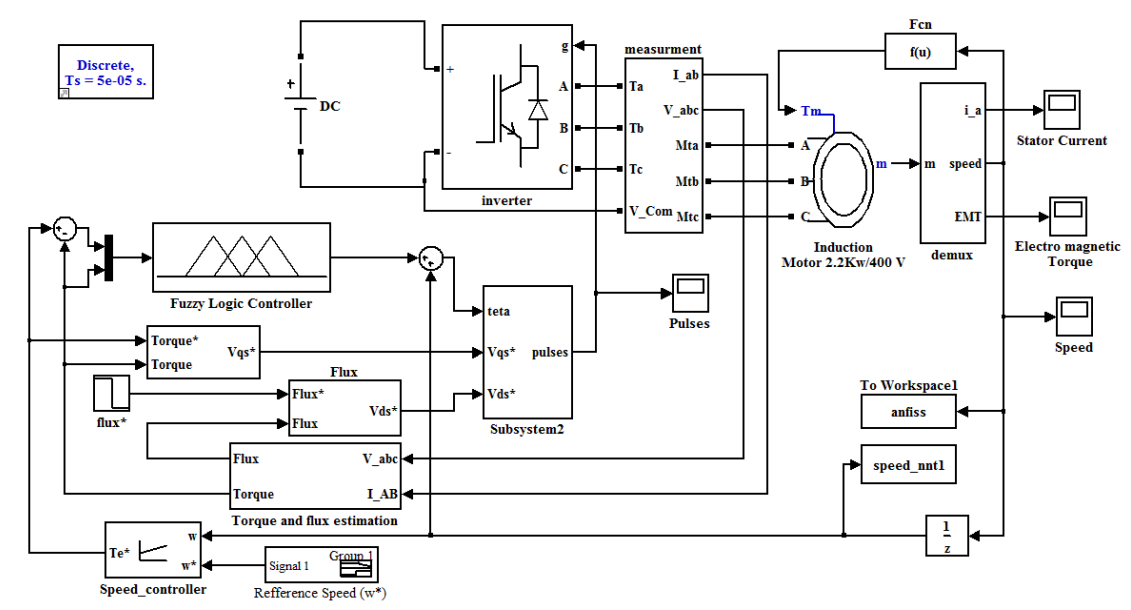

Figure 5: Simulink Model of Fuzzy Logic Speed control System. 


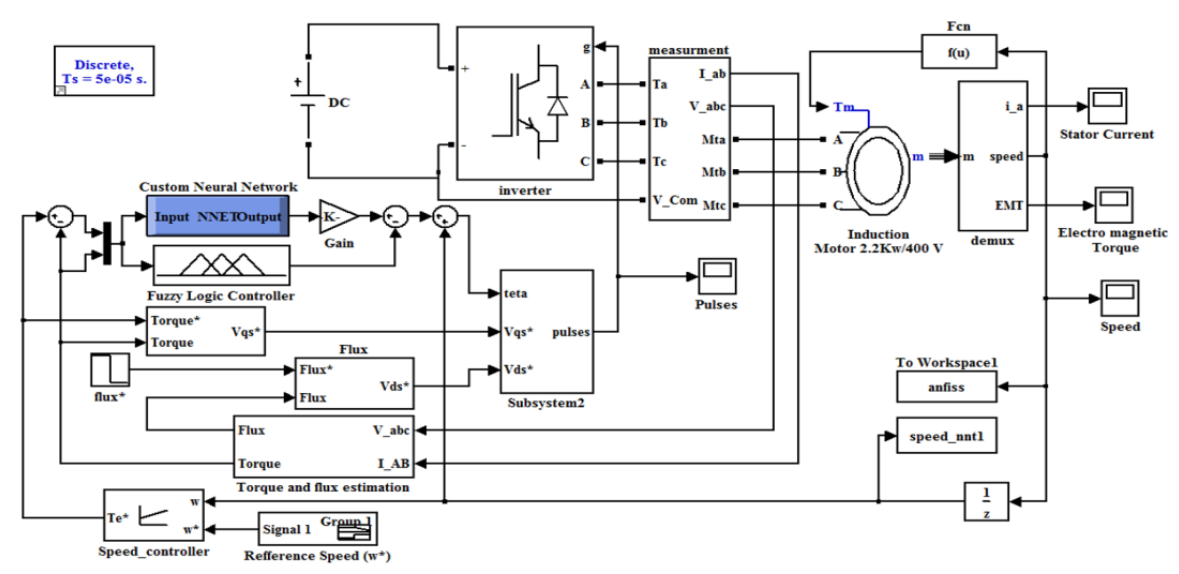

Figure 6: Simulink Model of Proposed (ANFIS) Speed control System.

\section{RESULTS AND DISCUSSION}

To describe the dynamic response of the IM choosing the speed set point is $80 \mathrm{rad} / \mathrm{sec}$ from rest at duration of $0.5 \mathrm{sec}$. Then the speed set point is varied from $80 \mathrm{rad} / \mathrm{sec}$ to $60 \mathrm{rad} / \mathrm{sec}$ at duration of $0.5 \mathrm{sec}$. After that the speed set point is varied from $60 \mathrm{rad} / \mathrm{sec}$ to $100 \mathrm{rad} / \mathrm{sec}$ at duration of $1 \mathrm{sec}$. The performance of current, voltage, flux, torque, speed of the motor with the fuzzy logic controller are depicted from Fig.7 to Fig. 11 respectively.

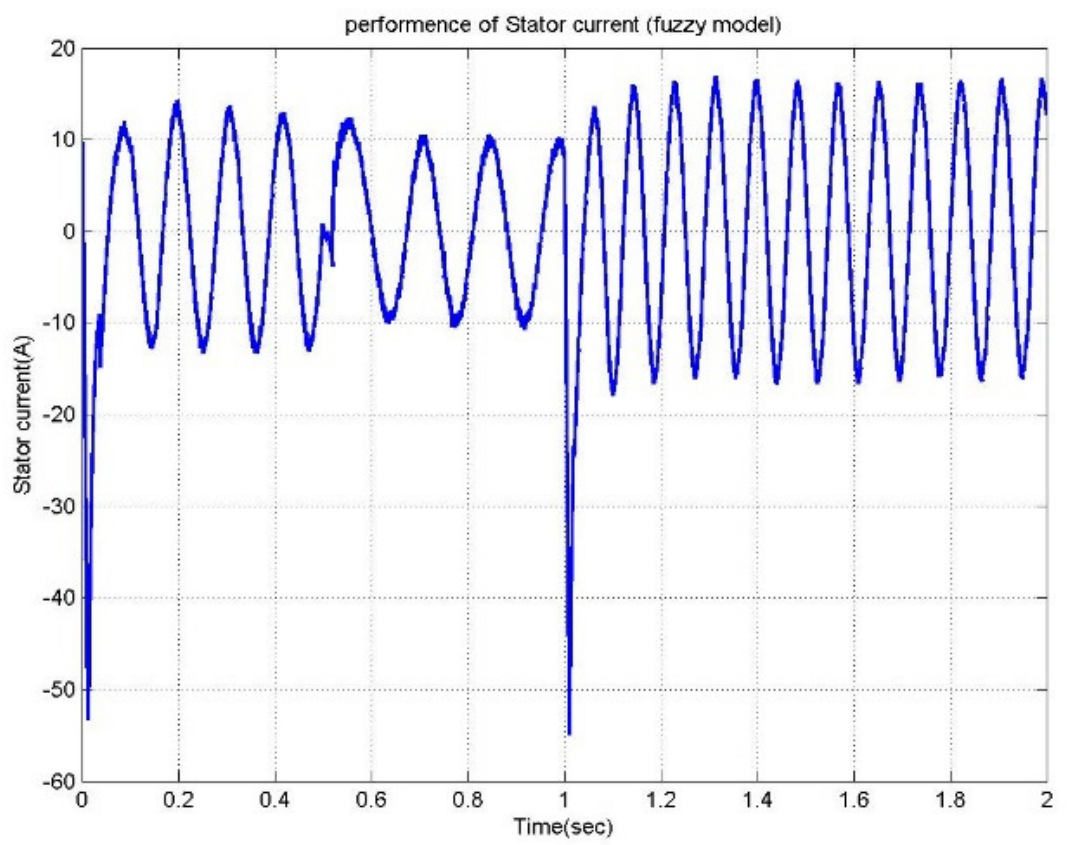

Figure 7: Dynamics of Stator Current. 
Electrical and Electronics Engineering: An International Journal (ELELIJ) Vol 3, No 2, May 2014

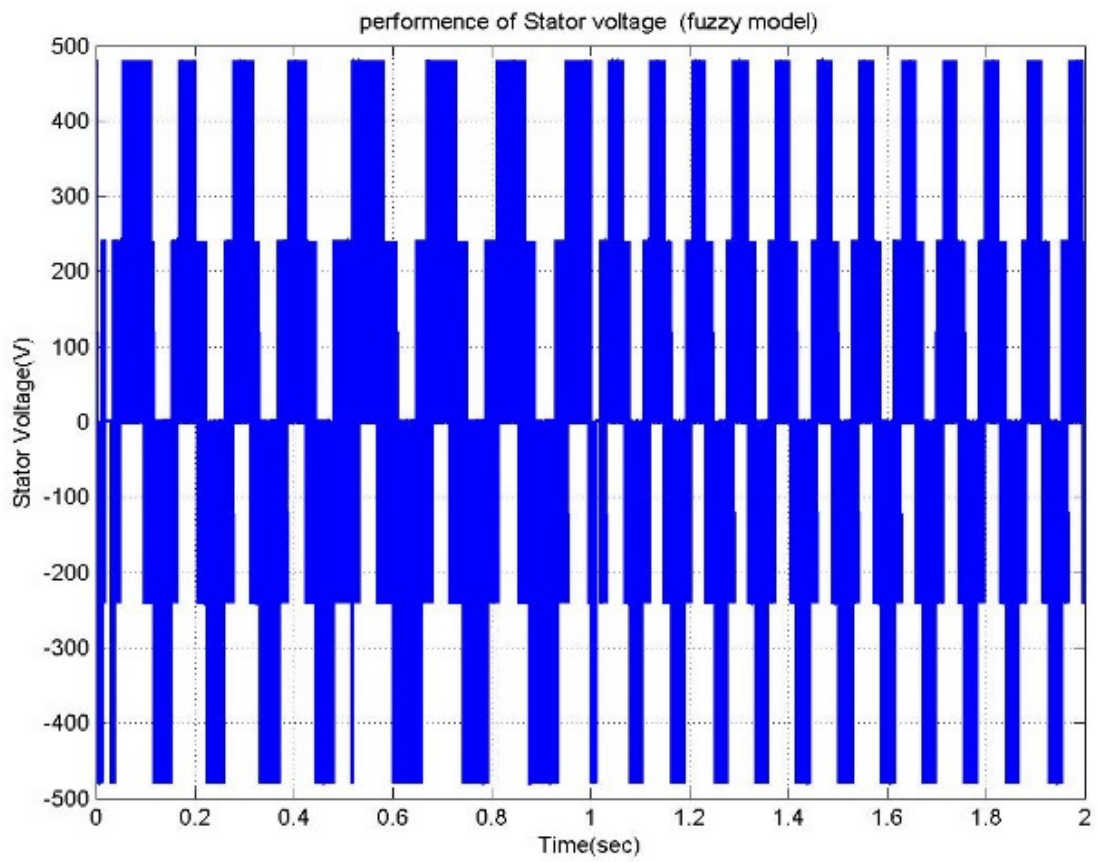

Figure 8: Transformed d-q axis of Stator Voltage.

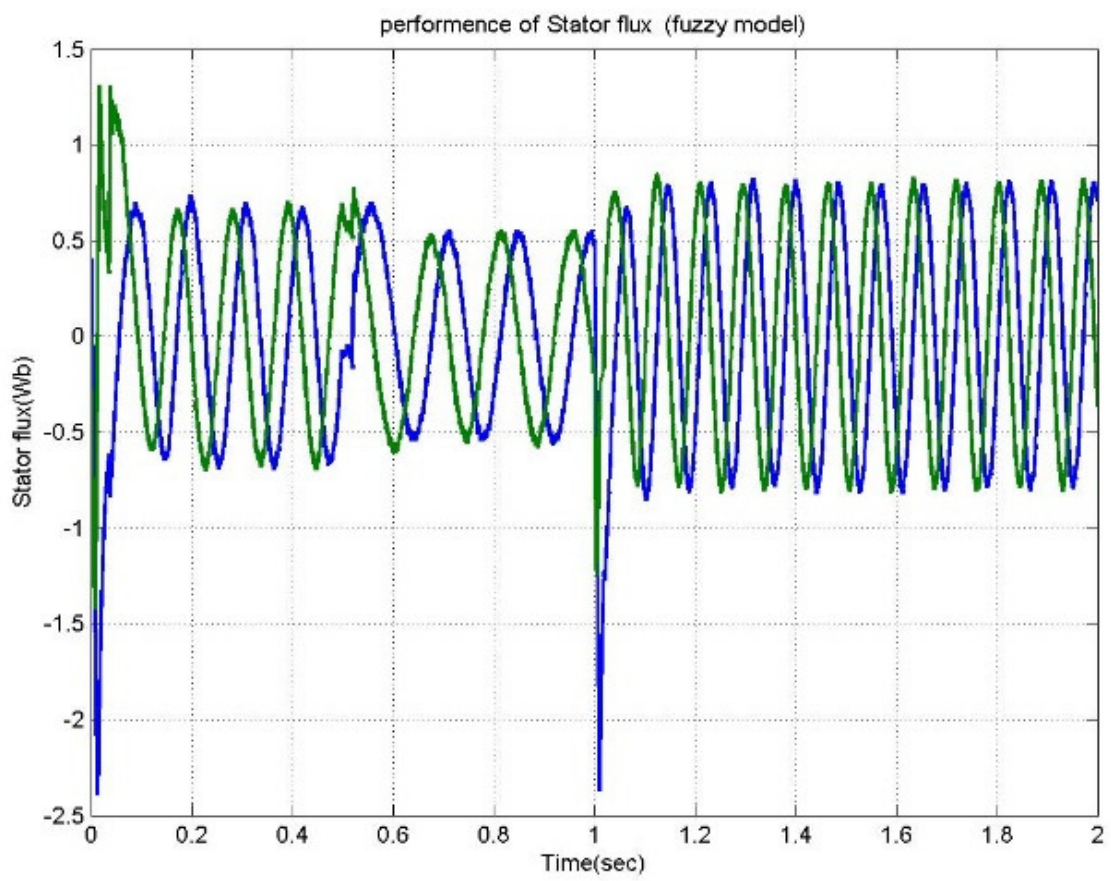

Figure 9: Dynamics of d-q axis Stator Flux. 
Electrical and Electronics Engineering: An International Journal (ELELIJ) Vol 3, No 2, May 2014

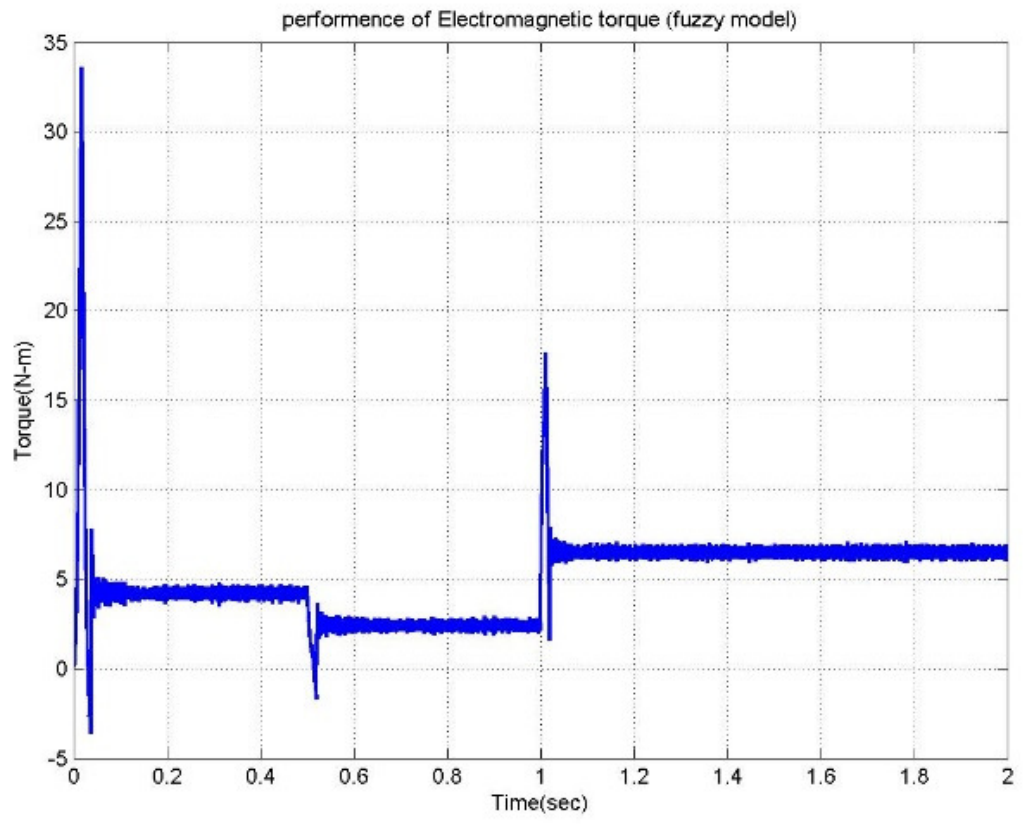

Figure 10: Variations of Electromagnetic Torque.

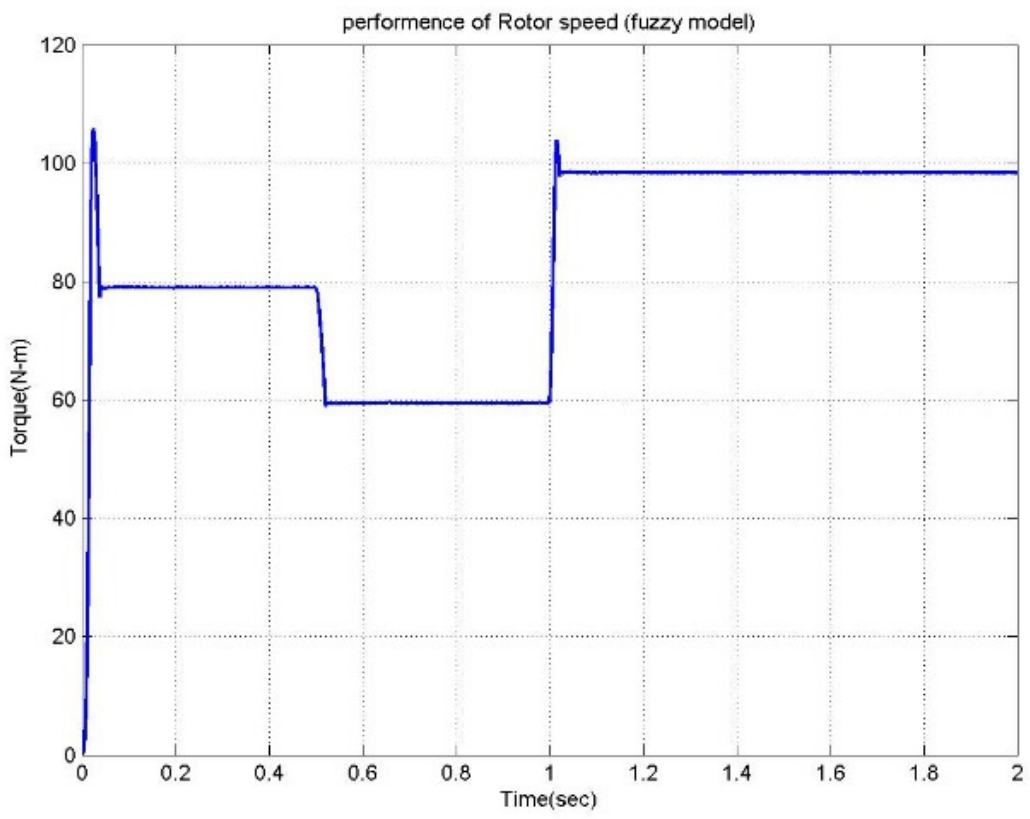

Figure 11: Performance of Speed.

The motor performance characteristics under the proposed adaptive neuro-fuzzy interference system are shown in Fig.12 to Fig.16 respectively. The speed of the motor with the Fuzzy logic controller and proposed ANFIS controller is compared in Fig.17. 
Electrical and Electronics Engineering: An International Journal (ELELIJ) Vol 3, No 2, May 2014

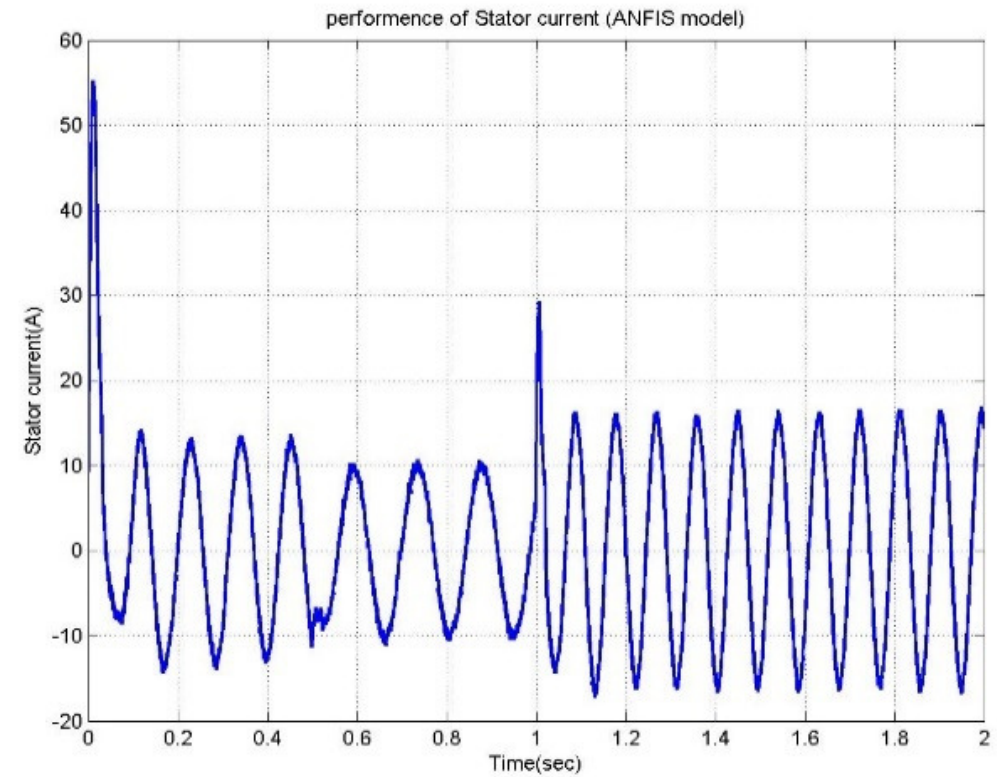

Figure 12: Dynamics of Stator Current.

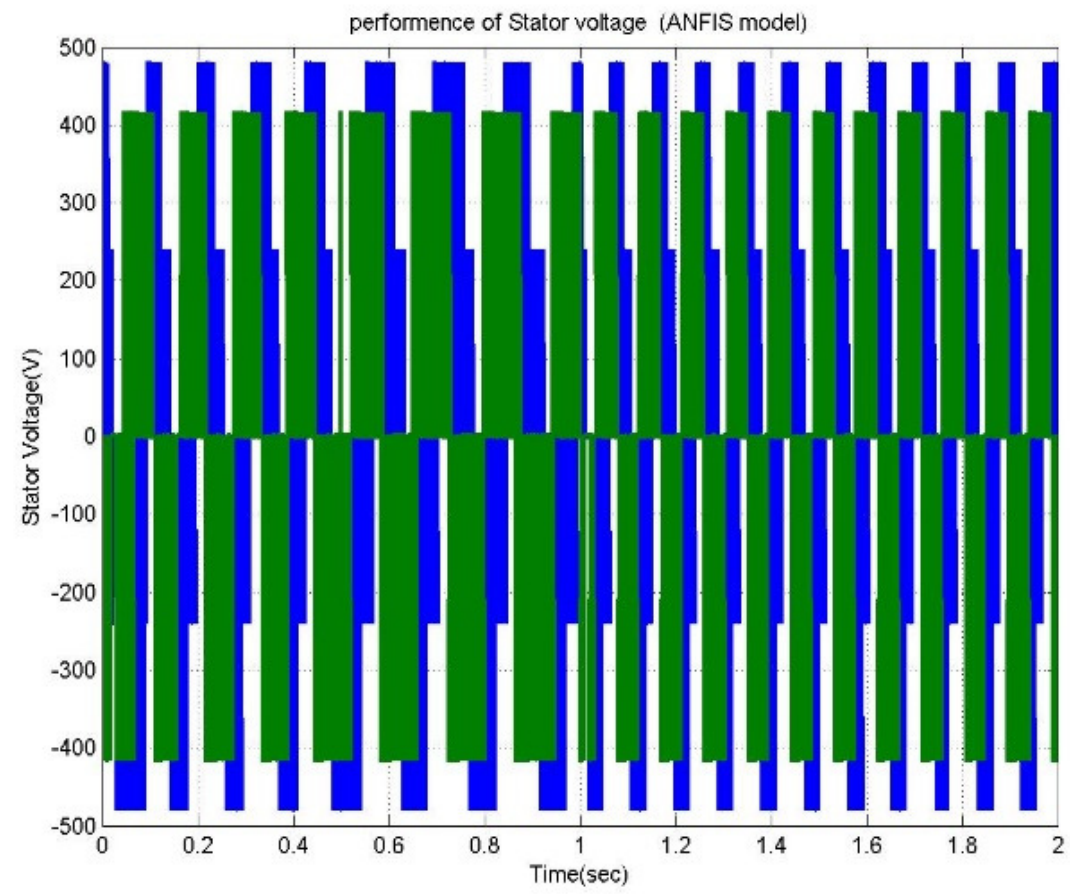

Figure 13: Transformed d-q axis of Stator Voltage. 
Electrical and Electronics Engineering: An International Journal (ELELIJ) Vol 3, No 2, May 2014

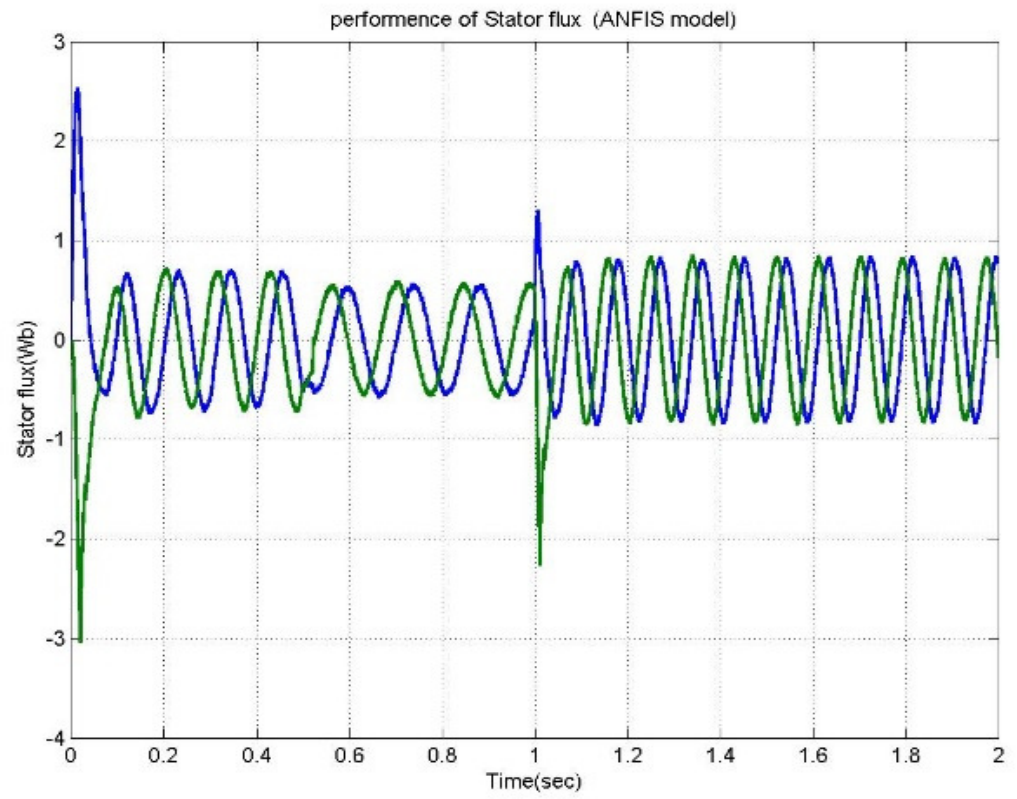

Figure 14: Dynamics of d-q axis Stator Flux.

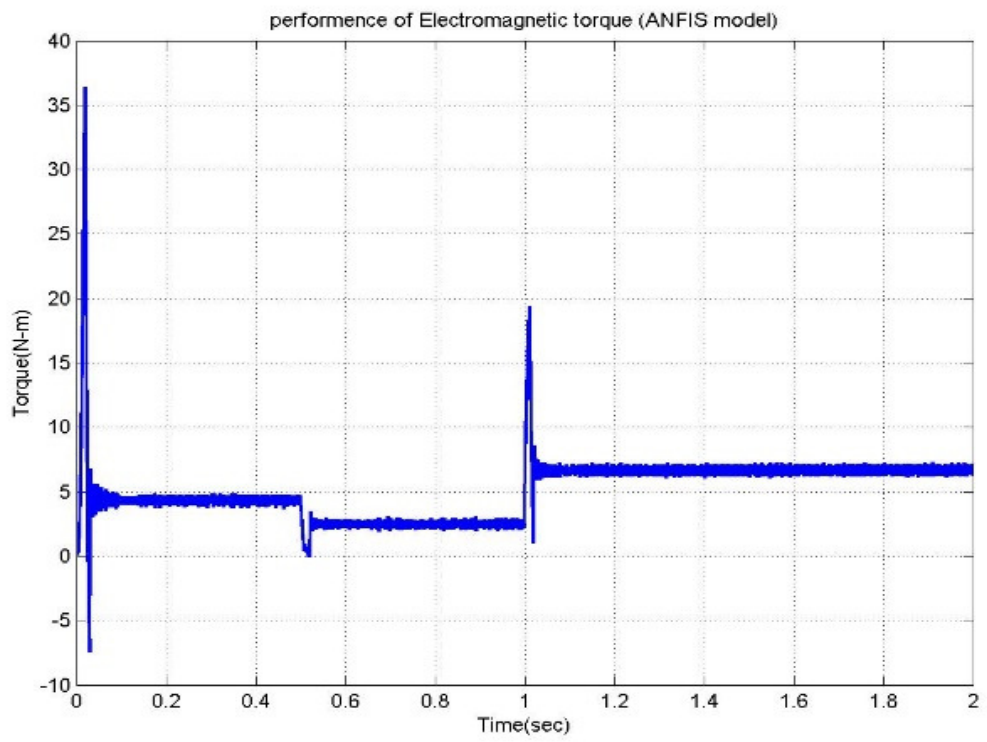

Figure 15: Variations of Electromagnetic Torque. 
Electrical and Electronics Engineering: An International Journal (ELELIJ) Vol 3, No 2, May 2014

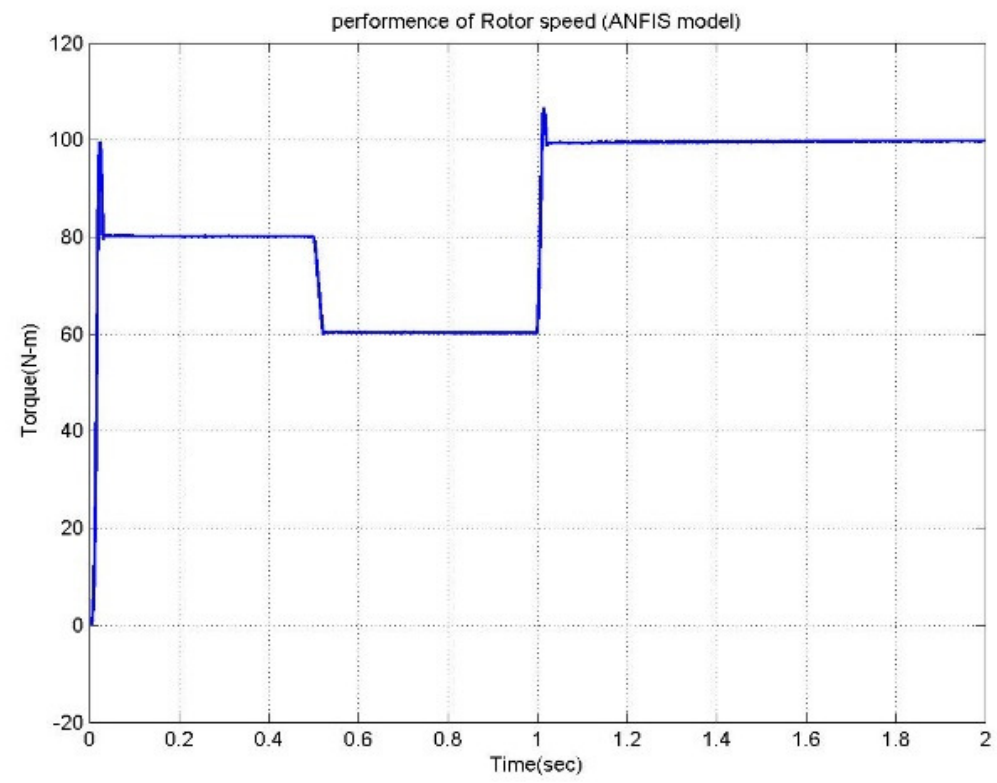

Figure 16: Performance of Speed.

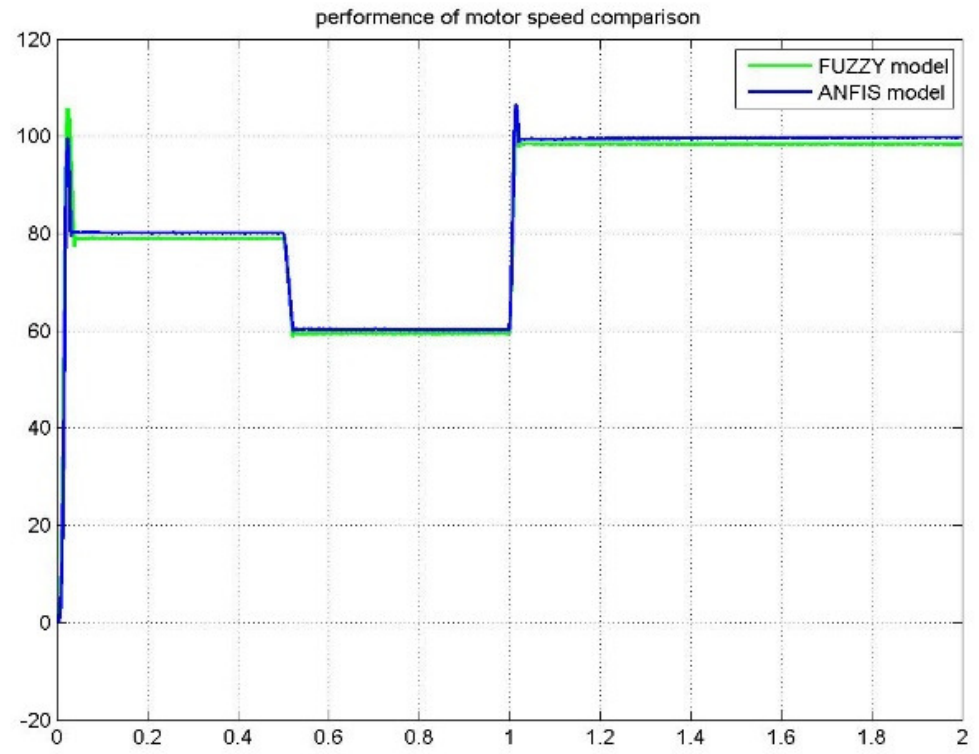

Figure 17: Comparison Performance of Rotor Speed.

From the comparative analysis, the proposed ANFIS speed controller provides smooth speed control performance with less settling time, peak overshoot and steady state error when compared to the Fuzzy logic controller. The fuzzy controller offers high overshoot, oscillations. Hence, the proposed ANFIS speed controller is better than fuzzy speed controller. 


\section{Conclusions}

The proposed ANFIS based DTC method was implemented in MATLB/SIMULINK platform. The performance of the proposed control technique was tested on $2.2 \mathrm{Kw} / 400 \mathrm{~V}$ induction motor. The mathematical model of the induction motor was analyzed in terms of stator voltage and torque equation. The actual torque and the change of toque of the motor were applied to the ANFIS and the electromagnetic torque was determined from the output of interference system. The output of ANFIS was converted into stator voltage and the stator voltage was applied to SVM. From the output of SVM, the control signal was generated to control the speed of the motor close to reference speed. The performance speed and the torque are analyzed and the analyzed performances are compared with fuzzy controller. From the comparative analysis, the proposed ANFIS speed control technique is better than fuzzy control technique.

\section{APPENDIX-A}

Table 1: Implementation parameters.

\begin{tabular}{|c|c|}
\hline Parameters & Values \\
\hline Nominal power & 2200 watts \\
\hline Line to line voltage & $400 \mathrm{volts}$ \\
\hline Frequency & $50 \mathrm{~Hz}$ \\
\hline Stator resistance & $3.67 \mathrm{ohm}$ \\
\hline Stator inductance & $0.0269 \mathrm{H}$ \\
\hline Rotor resistance & $2.1 \mathrm{ohm}$ \\
\hline Rotor inductance & $0.0269 \mathrm{H}$ \\
\hline Mutual inductance & $0.0324 \mathrm{H}$ \\
\hline Inertia & $0.0155 \mathrm{~kg} \cdot \mathrm{m} / 2$ \\
\hline Friction & $0.0025 \mathrm{~N} . \mathrm{m} . \mathrm{s}$ \\
\hline Number of poles & 2 \\
\hline
\end{tabular}

\section{REFERENCES}

[1] R.Rajendran and N.Devarajan,(2010) "FPGA Based Implementation of Space Vector Modulated Direct Torque Control for Induction Motor Drive", International Journal of Computer and Electrical Engineering, Vol.2, No.3, pp.589-594.

[2] Cosmas .U. Ogbuka and Marcel. U. Agu,(2011) "A Modified Approach to Induction Motor Stator Voltage and Frequency Control", Proceedings of the World Congress on Engineering, Vol.2.

[3] Nalin Kant Mohanty and Ranganath Muthu,(2011) "Implementation of Proportional Integral (PI) Controlled DSP Based Cost Effective Inverter Fed Speed Control of Induction Motor Drive with VisSim/ Embedded Controls and Developer (ECD)", International Journal of the Physical Sciences Vol. 6 ,No.20, pp. 4790-4797, 23 September.

[4] Anggun Anugrah, Rosli Omar, Marizan Sulaiman,Azhar Ahmad,(2005) "Fuzzy Optimization for Speed Controller of An Indirect Vector Controlled Induction Motor Drive Using Matlab Simulink", Journal of Theoretical and Applied Information Technology, Vol.28, No.2.

[5] Ehsan Hassankhan and Davood A. Khaburi, (2008)"DTC-SVM Scheme for Induction Motors Fed with a Three-level Inverter", World Academy of Science, Engineering and Technology, Vol.44, pp.168-172.

[6] Walid Emar, Hussein Sarhan, Rateb Al-Issa,Issam TTrad,Mahmoud Awad,(2011) "V/F Control of Squirrel Cage Induction Motor Drives Without Flux or Torque Measurement Dependency", International Journal of Robotics and Automation (IJRA), Vol. 2,No. 2. 
Electrical and Electronics Engineering: An International Journal (ELELIJ) Vol 3, No 2, May 2014

[7] Yeong-Hwa Chang, Chun-I Wu, Hung-Wei Lin and Nien-Der Kuo,(2011)"Robust Performance Control Of Vector-Controlled Induction Motors With Gain-Scheduled Estimation And Input-Output Linearization," International Journal of Innovative Computing, Information and ControlVol.7, No.1.

[8] Isao Takahashi and Toshihika Noguchi, (1986)"A New Quick-Response and High Efficiency Control Strategy for an Induction Motor", IEEE Transaction on Industry Application, Vol.22, No.5, pp.820827.

[9] T. G. Habetler, F. Profumo, M.Pastorelli, L. Tolbert,(1992) "Direct torque control of induction machines using space vector modulation," IEEE Transaction on Industry Applications, Vol.28, No.5, pp.1045-1053.

[10] A. K. Sharma, R. A. Gupta and Laxmi Srivastava,(2007) "Performance Of Ann Based Indirect Vector Control Induction Motor Drive", Journal of Theoretical and Applied Information Technology, Vol.3, No.3, pp.50-57.

[11] K. Srivastava, S. M. Tripathi,(2011) "Current Source Inverter fed Induction Motor Drives: A Survey", International Journal of Electrical Systems (IJES), Vol.1, No.1, pp. 14 27.

[12] Thanga Raj,S. P. Srivastava, and Pramod Agarwal,(2009) "Energy Efficient Control of Three-Phase Induction Motor - A Review", International Journal of Computer and Electrical Engineering, Vol.1, No.1, pp.1793-8198.

[13 ]M. Siva Satyanarayana, D. Subba Rayudu, T. Brahmananda Reddy and V. Sowmya Sree,(2011) "Comparison Of Vector Control Of Induction Motor Drive Using Conventional Method and Look Up Tables With 6- And 24- Sectors", International Journal of Engineering Science and Technology (IJEST), Vol. 3, No. 7.

[14] Vinod Kumar, R.R.Joshi,(2005) "Hybrid Controller based Intelligent Speed Control of Induction Motor", Journal of Theoretical and Applied Information Technology.

[15] Badre Bossoufi, Mohammed Karim, Silviu Ionita and Ahmed Lagrioui,(2011) "DTC Control Based Artificial Neural Network For High Performance PMSM Drive", Journal of Theoretical and Applied Information Technology, Vol33, No.2, pp.165-176.

[16] K.Ranjith Kumar,D.Sakthibala,S.Palaniswami,(2010) "Efficiency Optimization of Induction Motor Drive using Soft Computing Techniques", International Journal of Computer Applications Vol. 3, No.1, pp.0975 - 8887.

[17] Pundaleek. B. H.,Manish G. Rathi,Vijay Kumar M. G.,(2010) "Speed Control of Induction Motor: Fuzzy Logic Controller v/s PI Controller", IJCSNS International Journal of Computer Science and Network Security, Vol.10, No.10.

[18] Karim Negadi, Abdellah Mansouri, Belkheir Khtemi,(2010) "Real Time Implementation of Adaptive Sliding Mode Observer Based Speed Sensorless Vector Control of Induction Motor",Serbian Journal Of Electrical Engineering, Vol. 7, No. 2, pp.167-184.

[19] E. Siavashi, A. Pahlavanhoseini, R. Pejmanfar, A. Khanjanzadeh,(2011) "Using Clonal Selection Algorithm to optimize the Induction Motor Performance", Canadian Journal on Electrical and Electronics Engineering, Vol. 2, No. 9.

[20] Fatiha Zidani and Rachid Nait Said,(2005) "Direct Torque Control of Induction Motor with Fuzzy Minimization Torque Ripple", Journal of Electrical Engineering, Vol.56, No.7-8, pp.183-188.

[21] Ameur Fethi Aimer, et.al,(2009) "Application of Fuzzy Logic for a Ripple Reduction Strategy in DTC Scheme of a PWM Inverter fed Induction Motor Drives", Journal of electrical systems, No.1, pp.1317.

[22] S.M. Gadoue, D. Giaouris, and J.W. Finch,(2009) "Artificial intelligence-based speed control of DTC induction motor drives-A comparative study", Electric Power Systems Research, Vol.79, pp.210 219.

[23] Shu-Xi Liu, Ming-Yu Wang, Yu-Guang Chen and Shan Li,(2010) "A Novel Fuzzy Direct Torque Control System for Three-level Inverter-fed Induction Machine", International Journal of Automation and Computing, Vol.7, No.1, pp.78-85.

[24] Zhifeng Zhang, Renyuan Tang, Baodong Bai and Dexin Xie,(2010) "Novel Direct Torque Control Based on Space Vector Modulation With Adaptive Stator Flux Observer for Induction Motors", IEEE Transactions on Magnetics, Vol.46, No.8, pp.3133-3136.

[25] V. Talaeizadeh, R. Kianinezhad, S.G. Seyfossadat, and H.A. Shayanfar,(2010) "Direct torque control of six-phase induction motors using three-phase matrix converter", Energy Conversion and Management, Vol.51, pp.2482-2491.

[26] Tobias Geyer,(2011) "Computationally Efficient Model Predictive Direct Torque Control", IEEE Transactions on Power Electronics, Vol.26, No.10, pp.2804-2816. 
[27] Brahim Metidji, Ahmed Azib, Farid Tazerart, Nabil Taib and Toufik Rekioua,(2011) "Fuzzy Direct Torque Control with Torque Ripple Reduction for Induction Motor Drives fed by Matrix converters", International Journal of Research and Reviews in Computing Engineering, Vol.1, No.1, pp.23-28.

[28] Mohamad Reza Dastranj, Elahe Ebrahimi, Nemat Changizi and EsmaeilSameni,(2011) "Control DC Motorspeed with Adaptive Neuro-Fuzzy control (ANFIS)", Australian Journal of Basic and Applied Sciences, Vol.5, No.10, pp.1499-1504.

[29] Allirani S., and Jagannathan,(20120 "Direct Torque Control Technique for Voltage Source Inverter Fed Induction Motor Drive",International Journal of Electrical Engineering, Vol.5, No.5, pp.629-640.

[30] Zhifeng Gao, Peng Shi, and Yufei Xu ,2010) "Adaptive Fault-Tolerant Tracking Control of NearSpace Vehicle Using Takagi-Sugeno Fuzzy Models", IEEE Transactions on Fuzzy Systems, Vol.18, No.5, pp.1000-1007.

[31] Kasabov N.K., and Qun Song,(2002) "DENFIS: dynamic evolving neural-fuzzy inference system and its application for time-series prediction", IEEE Transactions on Fuzzy Systems, Vol.10, No.2, pp.144-154.

\section{Authors}

D.Chandra Sekhar received B.Tech Degree in Electrical and Electronics Engineering, M.Tech Degree in Power System Operation and Control in Electrical and Electronics Engineering from Sri Venkateswara University College of Engineering (Sri Venkateswara University) Tirupati,Andhra Pradesh, India in 2005 and 2009respectively.Currently he is pursuingPh.D. in Electrical and Electronics Engineering at Sri Venkateswaa UniversityCollege of Engineering,Sri Venkateswara University,in Tirupati, Andhra Pradesh, India.

G.Venkata Marutheswar received B.Tech Degree in Electrical Engineering,TheM.Tech (with Distinction) Degree in Instrumentation and Control Engineeringand Ph.D Degree in Electrical and Electronics Engineering from SriVenkateswara University Tirupati,Andhra Pradesh in 1985,1990 and2009,respectively.Currently he is working as a Professor in the department ofElectrical and Electronics Enginering,S.V.U.College

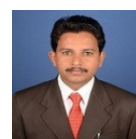
ofEngineerin g,Tirupati,Andhra Pradesh,India. 